\title{
Synthesis and Characterization of Zeolite Y From Bagasse Ash with Hydrothermal Temperatures Variations Using The Sol-Gel Method
}

\author{
Soifi Ali, Suci Amalia, A. Ghanaim Fasya, Susi Nurul Khalifah \\ Jurusan Kimia Fakultas Sains dan Teknologi UIN Maulana Malik Ibrahim Malang \\ Email: susikhalifah@gmail.com
}

\begin{abstract}
Zeolite Synthesis $\mathrm{Y}$ is done using sol-gel method on the molar composition of $10 \mathrm{Na}_{2} \mathrm{O}: 15 \mathrm{SiO}_{2}: \mathrm{x}$ $\mathrm{Al}_{2} \mathrm{O}_{3}: 300 \mathrm{H}_{2} \mathrm{O}$ with $\mathrm{Si} / \mathrm{Al}$ on ratio of 2,43 and hydrothermal temperatures variations of 60,80 and $100{ }^{\circ} \mathrm{C}$. Characterization includes XRD to discover crystallinity and the purity of zeolite, FTIR for the analysis of functional groups and of the surface width with the adsorption of methylene blue. XRD result shows that the formed zeolites $\mathrm{Y}$ is still mixed with zeolite $\mathrm{P}$, the best result in synthesis with hydrothermal temperatures of 80 ${ }^{\circ} \mathrm{C}$. FTIR analysis showsthat all zeolite synthesis contain a common functionO-Si-O/O-Al-O and double ring. The surface area of zeolite $\mathrm{Y}$ at 60,80 and $100{ }^{\circ} \mathrm{C}$ is 22,$5522 ; 23,0603$ and22,9898 $\mathrm{m}^{2} / \mathrm{gram}$.
\end{abstract}

Keywords: Bagasse, sol-gel, temperature hydrothermal, zeolite Y

\begin{abstract}
Abstrak
Sintesis zeolit $\mathrm{Y}$ dilakukan menggunakan metode sol-gel pada komposisi molar $10 \mathrm{Na}_{2} \mathrm{O}: \mathrm{xAl}_{2} \mathrm{O}_{3}$ : $15 \mathrm{SiO}_{2}: 300 \mathrm{H}_{2} \mathrm{O}$ dengan rasio $\mathrm{Si} / \mathrm{Al} 2,43$ dan variasi suhu hidrotermal 60,80 dan $100{ }^{\circ} \mathrm{C}$. Karakterisasi meliputi XRD untuk mengetahui kristalinitas dan kemurnian zeolit, FTIR untuk analisis gugus fungsi serta analisis luas permukaan dengan adsorpsi methylene blue. Hasil XRD menunjukkan zeolit $\mathrm{Y}$ yang terbentuk masih campuran dengan zeolit $\mathrm{P}$, hasil terbaik pada sintesis dengan suhu hidrotermal $80^{\circ} \mathrm{C}$. Analisis FTIR menunjukkan semua zeolit sintesis memiliki gugus fungsi O-Si-O/O-Al-O dan cincin ganda. Luas permukaan zeolit Y pada suhu 60, 80 dan $100{ }^{\circ} \mathrm{C}$ berturut-turut adalah 22,5522; 23,0603 dan 22,9898 ${ }^{2} / \mathrm{gram}$.
\end{abstract}

Kata kunci: Ampas tebu, sol-gel, suhu hidrotermal, zeolit Y

\section{PENDAHULUAN}

Abu ampas tebu atau lazimnya disebut abu bagasse dapat dimanfaatkan menjadi zeolit karena memiliki kandungan silika yang tinggi, yaitu sebesar 64,65\% (Hanafi dan Nandang, 2011) dan 88,7 \%. (Widati, dkk., 2010). Salah satu zeolit yang disintesis karena memiliki banyak manfaat ialah zeolit $\mathrm{Y}$. Zeolit $\mathrm{Y}$ termasuk jenis faujasit bisa digunakan sebagai katalis dalam pengolahan minyak mentah (Bhatia, 1990), sebagai penukar ion pada proses desalinasi air laut (Kiti, 2012) atau sebagai adsorben karena dapat memindahkan sulfur dioksida $\left(\mathrm{SO}_{2}\right)$ dari gas sisa (Saputra, 2006).

Zeolit $\mathrm{Y}$ dengan rasio $\mathrm{Si} / \mathrm{Al}$ antara $1,5-3$ dan rumus $\mathrm{Na}_{\mathrm{j}}\left[\left(\mathrm{AlO}_{2}\right)_{\mathrm{j}}\left(\mathrm{SiO}_{2}\right)_{192-}\right.$ j]. $\mathrm{zH}_{2} \mathrm{O}$ (Kasmui, dkk., 2008) disintesis menggunakan metode sol-gel dengan rasio Si/Al 2,43 (Fathizadeh dan Ordou, 2011) karena metode ini menghasilkan derajat kristalinitas dan kemurnian yang tinggi, memperkecil distribusi ukuran partikel, selain itu sintesisnya satu tahap (Ramimoghadam, dkk., 2012).

Salah satu faktor yang juga berpengaruh produk akhir zeolit ialah suhu hidrotermal. Pada penelitian ini suhu hidrotermal divariasi antara 60, 80 dan 100 ${ }^{\circ} \mathrm{C}$ karena, pada suhu $40{ }^{\circ} \mathrm{C}$ masih berupa amorf, suhu 60 dan $100{ }^{\circ} \mathrm{C}$ terbentuk zeolit $\mathrm{Y}$ dengan kristalinitas yang semakin tinggi seiring bertambahnya suhu, sedangkan pada suhu $120^{\circ} \mathrm{C}$ menghasilkan produk campuran antara zeolit Y dan P (gismondine) (Sang, dkk., 2005). Hasil sintesis dikarakterisasi menggunakan XRD (X-Ray Diffraction), FTIR (Fourier Transform Infra Red) dan analisis luas permukaan. 


\section{METODE PENELITIAN Bahan}

Bahan yang digunakan dalam penelitian adalah abu ampas tebu, $\mathrm{Al}_{2} \mathrm{O}_{3}$ p.a, $\mathrm{NaOH}$ p.a, methylen bluemerck dan akuades.

\section{Prosedur Penelitian}

Sintesis Zeolit Y

Sintesis zeolit $\mathrm{Y}$ dilakukan sesuai dengan komposisi molar berikut: $10 \mathrm{Na}_{2} \mathrm{O}: \mathrm{x}$ $\mathrm{Al}_{2} \mathrm{O}_{3}: 15 \mathrm{SiO}_{2}: 300 \mathrm{H}_{2} \mathrm{O}$ yaitu mencampur 2,53 gram $\mathrm{Al}_{2} \mathrm{O}_{3}, 3,25$ gram $\mathrm{NaOH}, 8,08$ gram abu ampas tebu dan 20,86 gram $\mathrm{H}_{2} \mathrm{O}$ dan diaduk selama 30 menit. Campuran dipindah ke dalam botol hidrotermal dan dieramkan selama 30 menit pada suhu kamar. Kemudian dikristalisasi pada variasi suhu 60, 80 dan $100^{\circ} \mathrm{C}$ selama 24 jam. Kristal yang terbentuk dicuci dengan air suling sampai $\mathrm{pH}=7-8$, kemudian dikeringkan pada suhu $100{ }^{\circ} \mathrm{C}$ selama 12 jam. Produk hasil sintesis selanjutnya dikarakterisasi.

\section{Karakterisasi}

Karakterisasi zeolit hasil sintesis dengan XRD dilakukan pada radiasi $\mathrm{Cu} \mathrm{K}_{\alpha}$ $(\lambda=1.5405 \AA)$ pada $40 \mathrm{kV}$ dan $30 \mathrm{~mA}$, pada sudut $2 \theta$ sebesar $5-60^{\circ}$ dan kecepatan scan $0,02 \%$ detik. Karakterisasi dengan FTIR dilakukan pada daerah bilangan gelombang $4000-400 \mathrm{~cm}^{-1}$. Penentuan luas permukaan dilakukan dengan adsorpsi methylen blue.

\section{HASIL DAN PEMBAHASAN Sintesis Zeolit Y}

Berdasarkan penelitian Amalia (2014) ampas tebu mengandung silika 44,6 $\%$ setelah dicuci dengan $\mathrm{HCl} 1 \mathrm{M}$ dan mayoritas berfasa amorf, sehingga bisa digunakan sebagai sumber silika pada sintesis zeolit $\mathrm{Y}$.

Sintesis zeolit $\mathrm{Y}$ dimulai dengan pencampuran bahan-bahan seperti abu bagasse, $\mathrm{NaOH}$, Alumina dan akuades. Campuran bahan dilarutkan dalam aquades sebagai langkah awal dari proses sol-gel yang merupakan reaksi hidrolisis serta kondensasi pada proses polimerisasi struktur inti zeolit yang terjadi pada saat proses pemeraman. Hidrolisis akan terjadi pada kondisi asam maupun basa, pada kondisi basa kemungkinan air berdisosiasi untuk menghasilkan nukleofilik berupa anion hidroksil yang akan menyerang silika. Pada proses pemeraman terjadi pelarutan dan represipitasi dari monomer silika menjadi struktur gel yang lebih kuat dengan melibatkan reaksi kondensasi.

Kristal yang tebentuk pada proses pemeraman masih memiliki kondisi yang kurang stabil, sehingga perlu dilakukan proses penguat hubungan antar kristal, salah satunya dengan proses hidrotermal yang bertujuan untuk menyeragamkan kisi-kisi kristal zeolit. Variasi suhu dilakukan 60, 80 dan $100{ }^{\circ} \mathrm{C}$ pada proses tersebut untuk mengetahui suhu terbaik pada sintesis zeolit Y.

Padatan yang terbentuk kemudian dicuci sampai $\mathrm{pH} 8$ untuk menetralkan kondisi zeolit yang diakibatkan oleh $\mathrm{NaOH}$ serta menghilangkan pengotor yang larut dalam air. Padatan hasil penyaringan dikeringakan untuk menghilangkan air yang terperangkap di rongga zeolit.

\section{Karakterisasi}

\section{X-Ray Diffraction (XRD)}

Analisis XRD digunakan untuk mengetahui kristalinitas dan kemurnian dari zeolit hasil sintesis. Hasil XRD dari sintesis zeolit Y dengan rasio Si/Al 2,43 dan variasi suhu hidrotermal ditunjukkan pada Gambar 1 .

Secara keseluruhan zeolit $\mathrm{Y}$ hasil sintesis tiga variasi suhu hidrotermal kristalinitasnya masih rendah karena intensitas puncak-puncak pada difraktogram masih kecil. Sedangkan kemurniannya relatif tinggi untuk suhu $80{ }^{\circ} \mathrm{C}$ karena hanya terbentuk satu puncak zeolit $\mathrm{P}$, sedangkan untuk suhu 60 terdapat dua puncak zeolit $\mathrm{P}$ dan 3 puncak zeolit $\mathrm{P}$ untuk suhu $100{ }^{\circ} \mathrm{C}$, karena secara umum sintesis zeolit $\mathrm{Y}$ dari bahan alam cenderung menghasilkan campuran antara zeolit $\mathrm{Y}$ dan zeolit $\mathrm{P}$ yang disebabkan pengaruh logam-logam pengotor yang terdapat pada sumber silikanya, seperti 
penelitiannya Kondru, dkk. (2011), dengan sumber silika dari abu terbang dan penelitian Khabuanchalad, dkk. (2008) dari abu sekam padi. Akan tetapi hasil sintesis secara keseluruhan zeolit $\mathrm{Y}$ yang terbentuk masih mendominasi dengan banyaknya puncakpuncak yang terbentuk pada ketiga difraktogram variasi suhu tersebut.

\section{Fourier Transform Infra Red (FTIR)}

Analisis FTIR digunakan untuk mengetahui gugus fungsi yang terdapat pada zeolit hasil sintesis. Hasil analisis zeolit $\mathrm{Y}$ hasil sintesis dengan FTIR ditunjukkan pada Gambar 2.

Interpretasi dari puncak-puncak yang terbentuk menyatkan bahwa zeolit hasil sintesis dari ketiga variasi suhu hidrotermal memiliki kriteria yang sama, karena mengandung gugus fungsidari semua zeolit yang tidak terpengaruh oleh perubahan struktur yaitu gugus O-T-O dengan $\mathrm{T}$ berupa $\mathrm{Si}$ atau Al. Gugus O-T-O terbaca pada disekitar daerah 1048, 670 dan $464 \mathrm{~nm}$.

Gugus yang tepengaruh oleh perubahan struktur merupakan gugus cincin ganda, dimana untuk zeolit jenis faujasit terlihat disekitar daerah $574 \mathrm{~nm}$.Sedangkan gugus $-\mathrm{OH}$ terlihat pada sekitar daerah 3446 dan $1048 \mathrm{~nm}$ yang mewakili adanya air yang masih terperangkap pada pori zeolit, sehingga dimungkinkan adanya gugus $\mathrm{Si}-\mathrm{H}$ yang terbaca pada sekitar daerah $2361 \mathrm{~nm}$.

\section{Penentuan Luas Permukaan dengan} Adsorpsi Methylene Blue

Penentuan luas permukaan zeolit menggunakan methylen blue memiliki kelebihan dalam segi operasional karena harganya relatif murah. Luas permukaan zeolit hasil sintesis ditandai dengan besarnya methylene blue yang diadsorp. Hasil pengukuran analisis luas permukaan ditunjukkan pada Tabel 1, yang menyatakan bahwa luas permukaan dari zeolit $\mathrm{Y}$ hasil sintesis paling besar ialah pada suhu hidrotermal $80^{\circ} \mathrm{C}$. Hal ini sesuai dengan data XRD yang menyatakan bahwa sintesis zeolit Y terbaik diantara tiga variasi suhu hidrotermal terbentuk pada suhu $80{ }^{\circ} \mathrm{C}$. Semakin sedikit campuran zeolit, maka semakin seragaman struktur zeolit yang terbentuk.

Tabel 1. Perbandingan luas permukaan zeolit hasil sintesis

\begin{tabular}{|c|c|}
\hline $\begin{array}{c}\text { Zeolit Y } \\
\text { sintesisvariasisuhu }\end{array}$ & $\begin{array}{c}\text { Luas permukaan } \\
\text { zeolit }\left(\mathrm{m}^{2} / \mathrm{g}\right)\end{array}$ \\
\hline $60^{\circ} \mathrm{C}$ & 22,5522 \\
\hline $80^{\circ} \mathrm{C}$ & 23,0603 \\
\hline $100^{\circ} \mathrm{C}$ & 22,9898 \\
\hline
\end{tabular}

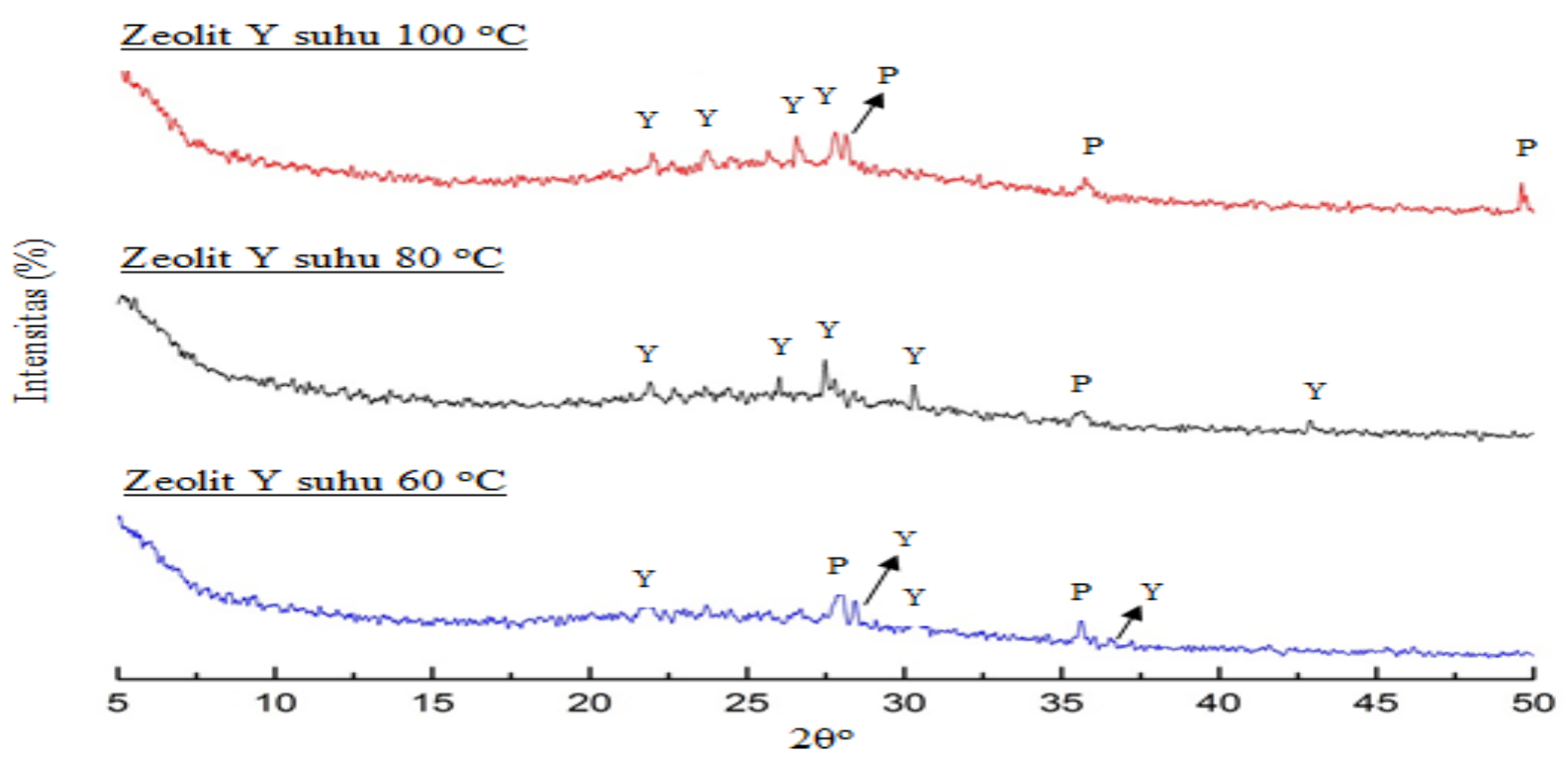

Gambar 1.Difraktogram Zeolit Y Sintesis 
Gambar 2.Spektra IR zeolit Y sintesis

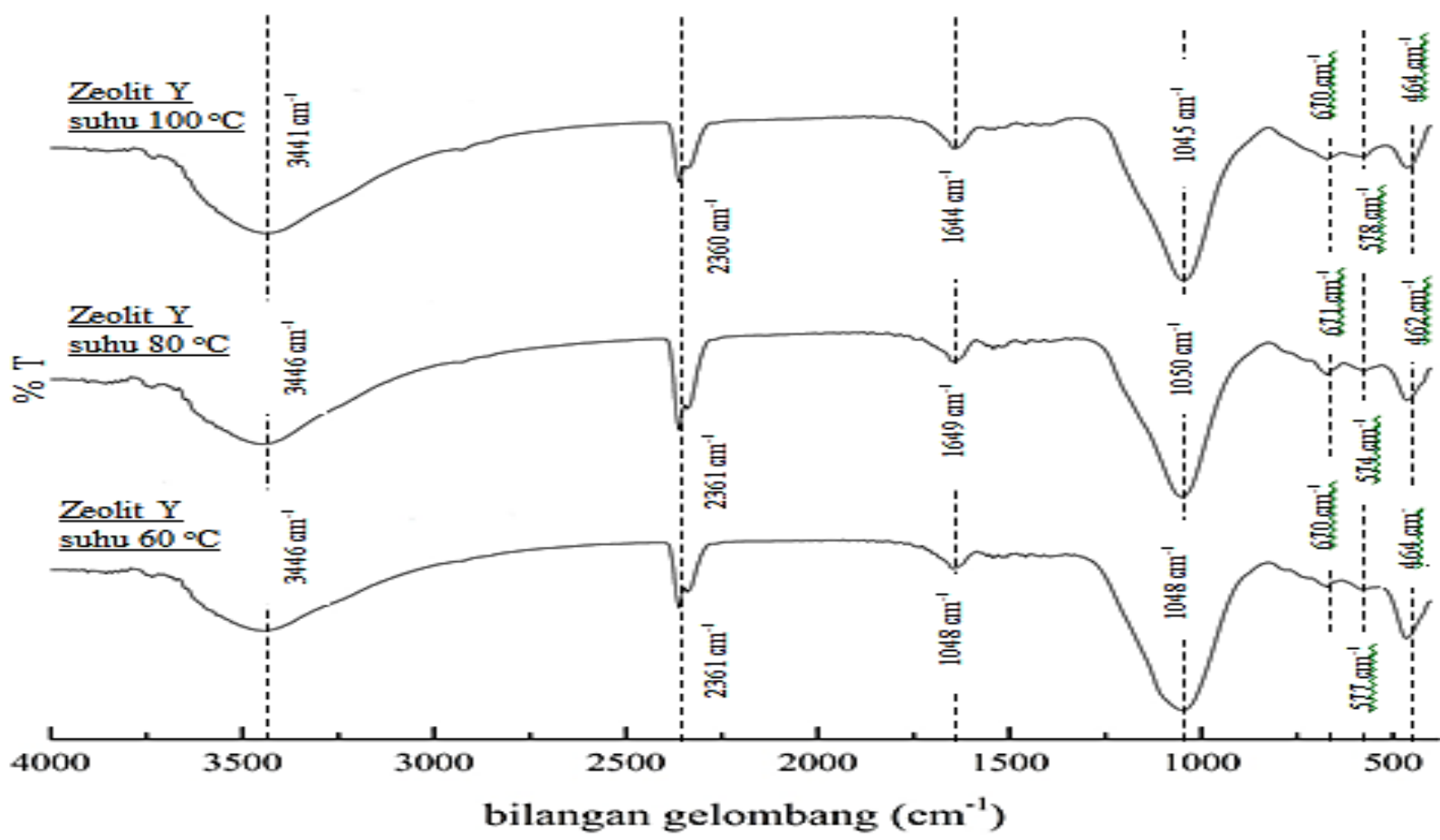

\section{KESIMPULAN}

Kemurnian tertinggi dari zeolit hasil sintesis diantara tiga variasi suhu hidroterma ialahl pada suhu $80{ }^{\mathrm{O}} \mathrm{C}$ berdasarkan hasil analisis XRD. Semua zeolit hasil sintesis memiliki gugus O-T-O dan cincin ganda, dengan $\mathrm{T}$ bisa $\mathrm{Si}$ atau $\mathrm{Al}$. Luas permukaan zeolit berbanding lurus dengan hasil XRD, yaitu luas permukaan paling besar terjadi pada suhu $80{ }^{\circ} \mathrm{C}=23,0603 \mathrm{~m}^{2} / \mathrm{g}$ sedangkan untuk suhu $60{ }^{\circ} \mathrm{C}=22,5522 \mathrm{~m}^{2} / \mathrm{g}$, dansuhu $100{ }^{\circ} \mathrm{C}=22,9898 \mathrm{~m}^{2} / \mathrm{g}$.

\section{DAFTAR PUSTAKA}

Amalia, S. 2014. Aktivitas Zeolit X dari Abu Ampas Tebu Sebagai Penukar Kation untuk Menurunkan Kesadahan Air. Penelitian Penguatan Program Studi. Malang: UIN MALIKI

Bhatia, S. 1990. Zeolite Catalysis: Principles andApplications. Florida: CRC Press.

Fathizadeh, M. Dan Ordou, N. 2011. Controlling Yield of $\mathrm{NaY}$ Zeolite Synthesis by Hydrothermal Method. Int. J. Ind. Chem. Vol. 2, No. 4, 2011, pp. 190-195.

Hanafi, A. dan Nandang, A. 2011. Studi Pengaruh Bentuk Silika dari Abu
Ampas Tebu terhadap Kekuatan

Produk Keramik. Jurnal Kimia Indonesia. 5 (1): 35-38.

Kasmui,Muhlisin, M.Z. dan Sumarni, W. 2008. Kajian Pengaruh Variasi Rasio Si/Al dan Variasi Kation Terhadap Perubahan Ukuran Pori Zeolit Y dengan Menggunakan Metode Mekanika Molekuler. Skripsi tidak diterbitkan. Semarang: Universitas Negeri Semarang.

Khabuanchalad, S., Khemthong, P., Prayoon pokarach, S. dan Wittayakun, J. 2008. Transformation of Zeolite $\mathrm{NaY}$ Synthesized from Rice Husk Silica to NaP During Hydrothermal Synthesis. Suranaree J. Sci. Technol. 15(3)

Kiti, E.V. 2012.Synthesis of Zeolites and Their Application to the Desalination of Seawater. Thesis. Kumasi: Kwame Nkrumah University of Science and Technology.

Kondru, A.K., Kumar, P., Teng, T.T., Chand, S. dan Wasewar, K.L. 2011.Synthesis and Characterization of Na-Y Zeolite from Coal Fly Ash and its Effectiveness in Removal of Dye from Aqueous Solution by Wet 
Peroxide Oxidation. ARCH. ENVIRON. SCI. 5, 46-54.

Ramimoghadam, D., Hussein, M.Z.B. dan Yap, Y.H.T. 2012. The Effect of Sodium Dodecyl Sulfate (SDS) and CetylTrimethyl Ammonium Bromide (CTAB) on the 10 Properties of $\mathrm{ZnO}$ Synthesize by Hydrothermal Method.Int J MolSci. 13:1327513293. doi:10.3390/ijms131013275.

Sang, S., Liu, Z., Tian, P., Liu, Z., Qu, L., Zhang, Y. 2005. Synthesis of small crystals zeolite NaY.Materials Letters. 60 (2006) 1131-1133.

Saputra, R. 2006. Pemanfaatan Zeolit Sintetis Sebagai Alternatif Pengolahan Limbah Industri. Buletin IPT, 1, IV, 8-20.

Widati, A.A., Baktir, A., Hamami, Setyawati, H.dan Rahmawati, R. 2010. Synthesis of Zeolite a from Baggase and Its Antimicrobial Activity on Candida albicans. Jurnal MIPA. 15 (2): 78-81 